\title{
Lethal and sub-lethal effects of bio-and chemical insecticides on the tomato leaf miner, Tuta absoluta (Meyrick) (Lepidoptera: Gelechiidae)
}

\author{
Mohamed A. Kandil, Rania N. Abdel-kerim and Moataz A. M. Moustafa*
}

\begin{abstract}
The tomato leaf miner, Tuta absoluta (Meyrick) (Lepidoptera: Gelechiidae), is a destructive pest affecting the tomato crop causing a loss of $60-100 \%$ of the tomato crop production. In the present study, the lethal and sub-lethal effects of Bacillus thuringiensis (Bt), spinosad, and emamectin benzoate as bio-insecticides comparing with 2 synthetic insecticides: chlorpyrifos and indoxacarb against $T$. absoluta under laboratory conditions were evaluated. Take in consideration, life tables and reproductive parameters of treated larvae with $L C_{30}$ for each pesticide (bioand chemical insecticides) by using leaf dipping technique were calculated. The results showed that Lepinox formulation of $B t$ was the most effective one against the early 2 nd instar larvae with $0.01 \times 10^{-2} \mathrm{mg} / \mathrm{l}(\mathrm{ppm})$, followed by spinosad with $0.07 \times 10^{-2} \mathrm{ppm}$ comparing to indoxacarb and chlorpyrifos $(0.01$ and $11.44 \mu \mathrm{g} / \mathrm{ml}$, respectively). Sub-lethal effect of the $B t$ formulations significantly increased pupal mortality by $29.77,33.30$, and 26.94\% for Lepinox, Dipel $2 x$, and Protecto, respectively. In addition to their efficiency, Bt formulations and emamectin benzoate increased larval developmental period and reduced adult emergency percentage to 70.28 , 66.70, 73.06, and 75.55\% for Lepinox, Dipel 2x, Protecto, and emamectin benzoate, respectively. All bio-insecticides including $B t$, spinosad, and emamectin benzoate caused abnormalities in different life stages. The results suggest these bio-insecticides are promising alternatives to synthetic insecticides for T. absoluta management.
\end{abstract}

Keywords: Tuta absoluta, Bacillus thuringiensis, Bio-insecticides, Chemical insecticides, Lethal effect

\section{Background}

The tomato leaf miner, Tuta absoluta (Meyrick) (Lepidoptera: Gelechiidae), is originated in Chile then spread to South America, Europe, and South East Asia. It has also moved south from the lowest Mediterranean shores into Africa on different solanaceous crops (Retta and Berhe 2015). Since its arrival to the Mediterranean basin, it becomes a key pest of tomato crop in open field and protected cultivation, making more than $80 \%$ losses in the tomato crop yield (CFIA 2010). In 2009, T. absoluta

\footnotetext{
*Correspondence: moataz.moustafa79@gmail.com

Department of Economic Entomology and Pesticides, Faculty of Agriculture, Cairo University, Giza 12613, Egypt
}

\section{Springer Open}

was recorded as invasive insect pest attacking tomato plants in Egypt (Mohammed 2010).

T. absoluta belongs to multivoltine species which has high reproductive potential in a short time. Meanwhile, it could adapt itself in a broad variation temperature, whilst under Mediterranean condition, T. absoluta observed 12 generations per year and does not diapause (Garcia and Vercher 2010). Its control by using chemical pesticides is extremely difficult and quite challenging. So, it could be controlled by a combination of all available control measures including physical, cultural, biological methods, and use of registered pesticides (Retta and Berhe 2015). Bio-pesticides that utilize beneficial microbial agents could reduce the reliance of

(c) The Author(s). 2020 Open Access This article is licensed under a Creative Commons Attribution 4.0 International License, which permits use, sharing, adaptation, distribution and reproduction in any medium or format, as long as you give appropriate credit to the original author(s) and the source, provide a link to the Creative Commons licence, and indicate if changes were made. The images or other third party material in this article are included in the article's Creative Commons licence, unless indicated otherwise in a credit line to the material. If material is not included in the article's Creative Commons licence and your intended use is not permitted by statutory regulation or exceeds the permitted use, you will need to obtain permission directly from the copyright holder. To view a copy of this licence, visit http://creativecommons.org/licenses/by/4.0/. 
chemical pesticides in its control. Thus, microbial agents could solve pressing needs as part of integrated pest management systems (Sayed and Behle 2017). Biopesticides based on B. thuringiensis (Bt) exhibited a potential role as an alternative strategy to control insect pests (Palma et al. 2014). The bio-insecticides spinosad and emamectin benzoate products have a high potent to a broad spectrum of lepidopterous pests on vegetables around the world, especially against $T$. absoluta (Gacemi and Guenaoui 2012).

It is a common phenomenon that arthropods are exposed to sub-lethal concentrations of pesticides because of their degradation after initial application in crops. Such exposure may lead to sub-lethal effects on all biological parameters, e.g., developmental rate, longevity, and fecundity (Chen et al. 2016). Therefore, determination of the sub-lethal effects of insecticides on insects is very important for elucidation the impact of pesticides on agroecosystem. These sub-lethal effects may be accompanied by an increase of some biological parameters such as fecundity and survival time, which was observed in the aphid species, Myzus persicae (Sulz.), after treatment with azadirachtin and imidacloprid (Culter et al. 2009).

The present work was carried out to evaluate the biological activities of the bio-insecticides, $B t$ formulations, spinosad, and emamectin benzoate, compared to the chemical insecticides: chlorpyrifos and indoxacarb on $T$. absoluta. In addition, assessing the sub-lethal effects of each compound on the developmental rate and reproductive potentiality of the pest under laboratory conditions.

\section{Materials and methods}

\section{Insect rearing}

T. absoluta samples were collected from tomato fields at Giza and Kalubia Governorates, Egypt, and transferred to the laboratory, where they were divided into groups in plastic plates for rearing at $25 \pm 2{ }^{\circ} \mathrm{C}, 60: 70 \% \mathrm{RH}$, and $16: 8$ light photoperiod regime in an incubator. Fresh leaves were provided daily to maintain the culture up to the 3rd generation (Deleva and Harizanova 2014) (Table 1).

\section{Tested bio-and chemical insecticides Bioassays}

Toxicity of the above insecticides on the 2nd instar larvae of $T$. absoluta was investigated, using the leaf dipping technique. Tomato leaves were collected from first to ninth node of the plants, where the leaves were greener and full of plant materials. Leaves were washed by water to ensure their cleanliness from any contaminants and cut in circular disks $(3 \mathrm{~cm}$ diameter). Six concentrations of each bio-insecticide were used, while in untreated control, the disks were dipped in tap water. Each leaf disk was dipped for $10 \mathrm{~s}$ beginning with the lowest concentration and continued ascending. Tissue culture plates ( 6 wells, $33.9 \mathrm{~mm}$, SPL Life Sciences Company) were used as vessels for study of toxicity. The bottom of each well of the plate was covered with thin layer of agar for moist. After drying at room temperature, five of 2 nd instar larvae were transferred by thin brush to each well and kept in an incubator. The treatment for each concentration was replicated six times. After $24 \mathrm{~h}$, the treated disks were replaced by untreated leaves disks for recording the daily mortality percent for 4 days. The insects were considered dead, when they were unable to move prodded with a fine brush (Galdino et al. 2011 and Deleva and Harizanova 2014).

\section{Sub-lethal effects of tested bio-and chemical insecticides}

The 2nd instar larvae of the 3rd generation of T. absoluta were used in experiments. The $\mathrm{LC}_{30}$ value of each insecticide was estimated as a sub-lethal concentration used in the study. The $\mathrm{LC}_{30}$ concentration was prepared by using the method described above. Three replicates, with 50 larvae each, were performed, and mortality rate was recorded and analyzed by probit analysis. In all treatments, the treated leaves after $24 \mathrm{~h}$ were replaced by untreated fresh leaves daily. Last instar larvae (4th instar larvae) were sexed following IRAC protocol (http://www.irac-online. org/methods/tuta-absoluta-larvae) and separated individually in glass tubes and then continued feeding till pupation. The pupae were weighted and transferred to clean

Table 1 Tested bio-and chemical insecticides and their rates of application

\begin{tabular}{llll}
\hline Insecticides (common name) & Trade names & Formulation active ingredient (a.i. \% ) & Recommended rate (g or ml/fed.) \\
\hline Bacillus thuringiensis & Lepinox & $3.75 \% \mathrm{WP}$ & $100 \mathrm{~g}$ \\
& Dipel 2x & $6.4 \% \mathrm{WP}$ & $200 \mathrm{~g}$ \\
& Protecto & $9.4 \% \mathrm{WP}$ & $300 \mathrm{~g}$ \\
Spinosad & Tracer & $24 \% \mathrm{SC}$ & $50 \mathrm{ml}$ \\
Emamectin benzoate & Proclaim & $5 \% \mathrm{SG}$ & $60 \mathrm{~g}$ \\
Chlorpyrifos & Dursban & $48 \% \mathrm{EC}$ & $100-125 \mathrm{ml}$ \\
Indoxacarb & Avaunt & $15 \% \mathrm{EC}$ & $25 \mathrm{ml}$
\end{tabular}

All Bt formulations equivalent to $32,000 \mathrm{IU} / \mathrm{mg}$ of Bacillus thuringiensis sp. kurstaki strain 
tubes to record pupation period. The sex ratio of adults was also recorded (Hafsi et al. 2012).

To assess the reproductive capacity, 4 groups of cross mating were used to elucidate the impact of sub-lethal effect. Cross mating experiment was conducted as follows: 1st group contained mating between untreated female + untreated male (control), 2nd group between treated female + untreated male, 3rd group between untreated female + treated male, and the 4th group between treated female + treated male. Number of deposited eggs was counted daily and transferred into glass jars till hatching to calculate hatchability rate, ovipositional periods, fecundity, and longevity of adults.

To estimate abnormalities and deformations, each treatment and control was replicated 3 times (50 larvae of the 2nd larval instar each), and percentage of abnormalities was calculated according to El-Tantawy and Salem (1976).

\section{Data analysis}

Mortality data from leaf dip bioassay were corrected, using Abbott's formula (Abbott 1925) to account natural mortality recorded in the control treatment. The statistical analysis program LDP line was used to determine the lethal and sub-lethal concentration values $\left(\mathrm{LC}_{30}\right.$, $\mathrm{LC}_{50}$, and $\mathrm{LC}_{90}$ ) for each bio-insecticide (with 95\% confidence limits). All biological parameters were performed using one-way ANOVA, followed by Duncan's multiple range test with the SPSS statistical analysis software.

\section{Results and discussion}

Toxicity of different bio-and chemical insecticides on 2 nd instar larvae of $T$. absoluta

Data setup in Table 2 showed the $\mathrm{LC}_{30}, \mathrm{LC}_{50}$, and $\mathrm{LC}_{90}$ values estimated for the tested insecticides against the 2nd instar larvae of T. absoluta under laboratory conditions using leaf dipping technique after 4 days of treatments. The results indicated that Lepinox " $B t$ " showed significantly the highest toxicity than spinosad with $\mathrm{LC}_{50}$ values of $0.0007 \mathrm{mg} / \mathrm{l}$ and $0.002 \mathrm{mg} / \mathrm{l}$, respectively, followed by emamectin benzoate $0.009 \mathrm{mg} / \mathrm{l} . \mathrm{LC}_{50}$ value was $0.11 \mathrm{mg} / \mathrm{l}$ for Dipel $2 \times$ " $B t$ " and $0.09 \mathrm{mg} / \mathrm{l}$ for indoxacarb. In addition, $\mathrm{LC}_{50}$ was $0.10 \mathrm{mg} / \mathrm{l}$ for Protecto " $B t$ ", while chlorpyrifos showed the lowest toxicity effect with $21.30 \mathrm{mg} / \mathrm{l}$. These results indicated that lepinox and Dipel $2 \times$ formulations of $B t$ and emamectin benzoate were the highly effective ones than indoxacarb and chlorpyrifos. These results are similar to those obtained by (Rausell et al. 2000 and Hashemitassuji et al. 2014) who found that 2nd and 3rd larval instars of T. absoluta that were susceptible to Bt. Hashemitassuji et al. (2014) mentioned that spinosad was more effective in the control of T. absoluta than Bt. Moreover, López et al. 2010 showed that emamectin benzoate was the most effective insecticide for control several lepidopteran pests and causing a reduction in the fecundity of females. While Hafsi et al. (2012) evaluated the toxicity of 13 insecticides against $T$. absoluta, and reported that the most 3 effective insecticides were $B t$, spinotram, and Spinosad, meanwhile, they were statistically similar. Thus, $B t$ caused a significant mortality percent after treated the 2nd instar larvae of $T$. absoluta with different products of $B t$ such as Protecto, Dipel $2 \times$, and Lepinox (Giustolin et al. 2001). Worthwhile, the inferior effectiveness of chlorpyrifos and indoxacarb may be due to their intensive used against $T$. absoluta, and consequently the insect became more resistant to these both insecticides. Moreover, insecticides are subjected to degradation after application. Consequently, the target pest was exposed to low concentrations of insecticides. Therefore, studies on the sub-lethal effects of insecticides on the target pests of great importance are to explore their indirect effectiveness, especially in the case of bio-insecticides or insect growth regulators.

Table 2 Toxicity of the tested bio-and chemical insecticides against the early 2nd instar larvae of Tuta absoluta (treated by leaf dipping technique)

\begin{tabular}{|c|c|c|c|c|}
\hline $\begin{array}{l}\text { Bio-and chemical insecticides } \\
\text { formulations }\end{array}$ & ${ }^{\mathrm{a}} \mathrm{LC}_{30}(\mathrm{mg} / \mathrm{l}), 95 \%{ }^{\mathrm{d}} \mathrm{CL}$ & ${ }^{b} \mathrm{LC}_{50}(\mathrm{mg} / \mathrm{l}), 95 \%{ }^{\mathrm{d}} \mathrm{CL}$ & ${ }^{\mathrm{L}} \mathrm{C}_{90}(\mathrm{mg} / \mathrm{l}), 95 \%{ }^{\mathrm{d}} \mathrm{CL}$ & Slope \pm SE \\
\hline Lepinox (Bt) & $0.01 \times 10^{-2}\left(0.06 \times 10^{-3}-0.08 \times 10^{-1}\right)$ & $0.07 \times 10^{-2}\left(0.09 \times 10^{-3}-0.13 \times 10^{-1}\right)=31085 \mathrm{IU} / \mathrm{mg}$ & $0.02(0.03-0.05)$ & $0.70 \pm 0.06$ \\
\hline Dipel 2× (Bt) & $0.09 \times 10^{-1}\left(0.03 \times 10^{-1}-0.20 \times 10^{-1}\right)$ & $0.11(0.06-0.50)=203.66 \mathrm{IU} / \mathrm{mg}$ & $9.89(8.66-16.14)$ & $0.48 \pm 0.05$ \\
\hline Protecto (Bt) & $0.14 \times 10^{-1}\left(0.59 \times 10^{-2}-0.229 \times 10^{-1}\right)$ & $0.10(0.05-0.13)=224.0 \mathrm{IU} / \mathrm{mg}$ & $11.79(3.35-23.77)$ & $0.65 \pm 0.06$ \\
\hline Spinosad & $0.07 \times 10^{-2}\left(0.04 \times 10^{-3}-0.001\right)$ & $0.002(0.001-0.004)$ & $0.08(0.05-0.21)$ & $0.85 \pm 0.07$ \\
\hline Emamectin benzoate & $0.03 \times 10^{-1}\left(0.01 \times 10^{-1}-0.05 \times 10^{-1}\right)$ & $0.009\left(0.06 \times 10^{-1}-0.12 \times 10^{-1}\right)$ & $0.10(0.07-0.25)$ & $1.22 \pm 0.18$ \\
\hline Chlorpyrifos & $11.44(5.7-15.9)$ & $21.30(13.21-32.78)$ & $97.24(72.75-272.9)$ & $1.94 \pm 0.16$ \\
\hline Indoxacarb & $0.01\left(0.04 \times 10^{-1}-0.20 \times 10^{-1}\right)$ & $0.09(0.05-0.17)$ & $24.87(10.68-78.19)$ & $0.53 \pm 0.04$ \\
\hline
\end{tabular}

${ }^{\mathrm{L}} \mathrm{LC}_{30}$ : concentration causing $30 \%$ mortality

${ }^{\mathrm{b}} \mathrm{LC}_{50}$ : concentration causing $50 \%$ mortality

${ }^{\mathrm{LCC}} \mathrm{Co}_{90}$ : concentration causing $90 \%$ mortality

${ }^{\mathrm{d}} \mathrm{CL}$ : confidence limits 
Latent effects of bio-and chemical insecticides on the 2 nd instar larvae

Data in Table 3 evaluated the latent effect of the tested bio-insecticides on the 2nd instar larvae of T. absoluta due to exposure to sub-lethal concentration of $\mathrm{LC}_{30}$ for $24 \mathrm{~h}$. Results showed elongating developmental period of larvae by about $6.64-1.44$ days at all treatments. Time to pupate was significantly longer for Dipel $2 \times$ by about 2.6 days, conversely indoxacarb larvae lasted (6.98 days) to pupate compared to the control (6.62 days). The pupation percent decreased significantly $(48.67 \pm 1.76 \%)$ in case of the emamectin benzoate; however, it was slightly differ than the control in case of the larvae treated with chlorpyrifos, as it was $(93.61 \pm 1.85 \%)$ and for untreated larvae as it was $(98.00 \%)$. Concerning the pupal weight, spinosad showed a significant increase in female weight $(0.31 \pm 0.01 \mathrm{mg})$ and Lepinox $(0.25 \pm 0.00) \mathrm{mg}$ than the control $(0.20 \pm 0.01 \mathrm{mg})$. However, emamectin benzoate showed an increase in male pupal weight $(0.35 \pm 0.00$ $\mathrm{mg})$, at variance indoxacarb $(0.24 \pm 0.01 \mathrm{mg})$ compared to the control $(0.22 \pm 0.01)$.

\section{Latent effect of bio-and chemical insecticides on adult stage}

Results in Table 4 present the developmental parameters of adult stage. Emergence \% was highly reduced post treatment with Dipel $2 \times$; meanwhile, chlorpyrifos did not exhibit any significant difference than control. Regarding the sex ratio of emerged adults, as shown in the results, spinosad led to increase adult sex ratio to $2: 1 \mathrm{fe}-$ male: male ratio, although emamectin benzoate caused a slight change in this ratio to be $+1 \hat{0} 1: 1.2$. For the adult longevity, the results showed fluctuated effect. All tested agents, except emamectin benzoate, decreased the adult longevity, especially in case of Protecto, which decreased adult longevity to 14.67 and 12.6 days for both females and males, respectively. In all bio-insecticides treatments, the pre-oviposional period was increased, especially in case of Dipel $2 \times$ (with 8.0 days). However, synthetic insecticides (indoxacarb and chlorpyrifos) did not differ than control. Moreover, it is clear from the results that all insecticides treatments had negative affect on the ovipositional period.

\section{Deformations shapes in different developmental stages}

Data in Table 5 demonstrate the means of deformation of different developmental stages. The results indicated that Lepinox showed the highest impact, and the incidence of deformation of larval and pupal percent was $28.33 \pm 0.33 \%$ and $10.83 \pm 2.49 \%$, respectively. However, emamectin benzoate caused a slight deformed larval percent $(2.85 \pm 1.43 \%)$ than the control, and the highest deformed adult's percent with $38.42 \pm 3.24 \%$ for adult females and $26.85 \pm 3.34 \%$ for adult males. In addition, spinosad caused the lowest deformed pupae percent with $2.63 \pm 2.59 \%$ and also in females with $2.56 \pm 2.56 \%$. As well, the lowest deformed males were found in case of Protecto with $11.43 \pm 5.95 \%$. Thus, all $B t$ formulations had obtained deformations in all life stages expect egg stage, contrary of chlorpyrifos, and indoxacarb, which did not cause any deformations.

\section{Latent effect on fecundity and fertility}

A broad range of variations in fecundity of T. absoluta was detected in all treatments (Fig. 1a). The results of mating between treated females $\times$ treated males showed that the females' fecundity was $267.33 \pm 97.27 \mathrm{egg} / \mathrm{fe}-$ male after treated the larvae with chlorpyrifos (Fig. 1a); otherwise, Dipel $2 \times$ gave the lowest number of eggs per female (43.27 \pm 24.22 eggs) compared to control (314.87 \pm 19.48 eggs). Besides, the total numbers of eggs of mating group between treated females + untreated males were $73.63 \pm 48.86$ eggs, when treated the 2 nd instar larvae with Dipel $2 \times$ (Fig. 1c), while emamectin benzoate

Table 3 Effects of the sub-lethal concentration, $L_{30}$ value, of tested bio-and chemical insecticides on the development parameters of Tuta absoluta from 2nd instar larvae to eclosion

\begin{tabular}{|c|c|c|c|c|c|c|}
\hline \multirow{3}{*}{$\begin{array}{l}\text { Insecticides } \\
\text { formulations }\end{array}$} & \multicolumn{6}{|c|}{ Duration (mean \pm SE) } \\
\hline & \multirow[t]{2}{*}{ *Larval } & \multirow[t]{2}{*}{ **Pupal } & \multirow{2}{*}{$\begin{array}{l}\text { Pupal } \\
\text { mortality \% }\end{array}$} & \multirow[t]{2}{*}{ Pupation \% } & \multicolumn{2}{|c|}{ Pupal weight (mg) } \\
\hline & & & & & Female & Male \\
\hline Control & $6.08^{f} \pm 0.91$ & $6.62^{d} \pm 0.96$ & $0.68^{e} \pm 0.68$ & $98.00^{a} \pm 0.00$ & $0.20^{\mathrm{e}} \pm 0.01$ & $0.22^{b} \pm 0.01$ \\
\hline Lepinox (Bt) & $9.12^{c} \pm 0.20$ & $7.41^{b c} \pm 0.16$ & $29.77^{\mathrm{ab}} \pm 0.55$ & $67.33^{b} \pm 3.71$ & $0.25^{d} \pm 0.00$ & $0.27^{b} \pm 0.01$ \\
\hline Dipel 2x (Bt) & $8.37^{d} \pm 0.11$ & $9.22^{\mathrm{a}} \pm 0.33$ & $33.30^{\mathrm{a}} \pm 1.43$ & $70.00^{b} \pm 1.15$ & $0.27^{c d} \pm 0.00$ & $0.26^{b} \pm 0.01$ \\
\hline Protecto (Bt) & $12.72^{\mathrm{a}} \pm 0.71$ & $8.02^{b} \pm 0.21$ & $26.94^{\mathrm{ab}} \pm 6.02$ & $66.67^{b} \pm 6.67$ & $0.30^{\mathrm{ab}} \pm 0.01$ & $0.30^{b} \pm 0.00$ \\
\hline Spinosad & $7.52^{\mathrm{e}} \pm 0.18$ & $7.13^{c d} \pm 0.28$ & $21.39^{b c} \pm 2.9$ & $52.00^{\mathrm{cd}} \pm 4.0$ & $0.31^{a} \pm 0.01$ & $0.33^{b} \pm 0.01$ \\
\hline Emamectin benzoate & $10.44^{b} \pm 0.26$ & $7.84^{b} \pm 0.26$ & $24.45^{\mathrm{ab}} \pm 3.17$ & $48.67^{d} \pm 1.76$ & $0.27^{c d} \pm 0.01$ & $0.35^{a} \pm 0.00$ \\
\hline Chlorpyrifos & $8.3^{d} \pm 0.18$ & $7.45^{b c} \pm 0.16$ & $6.39 d^{e} \pm 1.85$ & $93.61^{\mathrm{a}} \pm 1.85$ & $0.28^{b c} \pm 0.01$ & $0.28^{b} \pm 0.01$ \\
\hline Indoxacarb & $8.05^{d} \pm 0.15$ & $6.98^{\mathrm{cd}} \pm 0.2$ & $13.93^{\mathrm{cd}} \pm 0.97$ & $60.00^{b c} \pm 1.15$ & $0.26^{d} \pm 0.01$ & $0.24^{b} \pm 0.01$ \\
\hline
\end{tabular}

Values marked with the same letters are not significantly different $(P>0.05$ : Duncan's multiple range tests).

*number of days from 2 nd instar larvae till pupation, ${ }^{* *}$ number of days from pupae till the eclosion 
Table 4 Effects of tested bio-and chemical insecticides on the adult stage of . Tuta absoluta results from treated the 2nd instar larvae with the sub-lethal concentration of $\mathrm{LC}_{30}$ value

\begin{tabular}{|c|c|c|c|c|c|c|c|c|}
\hline \multirow{3}{*}{$\begin{array}{l}\text { Bio-and chemical } \\
\text { insecticides } \\
\text { formulations }\end{array}$} & \multicolumn{8}{|l|}{ Mean \pm SE } \\
\hline & \multirow[t]{2}{*}{ Emergence \% } & \multicolumn{2}{|l|}{ Sex ratio } & \multicolumn{2}{|c|}{ Longevity (days) } & \multirow{2}{*}{$\begin{array}{l}\text { Pre- } \\
\text { oviposition } \\
\text { (days) }\end{array}$} & \multirow{2}{*}{$\begin{array}{l}\text { Oviposion } \\
\text { period (days) }\end{array}$} & \multirow{2}{*}{$\begin{array}{l}\text { Post- } \\
\text { oviposition } \\
\text { (days) }\end{array}$} \\
\hline & & Females & Males & Females & Males & & & \\
\hline Control & $99.32^{a} \pm 0.86$ & $52.05^{c d} \pm 0.6$ & $47.95^{\mathrm{ab}} \pm 0.59$ & $18.00^{\mathrm{a}} \pm 0.58$ & $15.33^{a} \pm 0.67$ & $1.00^{c} \pm 0.00$ & $13.67^{\mathrm{ab}} \pm 0.67$ & $2.00^{\mathrm{a}} \pm 0.00$ \\
\hline Lepinox (Bt) & $70.28^{\mathrm{de}} \pm 0.6$ & $60.19^{\mathrm{abc}} \pm 5.95$ & $39.81^{b c d} \pm 5.95$ & $16.67^{b} \pm 0.33$ & $13.67^{\mathrm{ab}} \pm 0.33$ & $4.33^{b} \pm 0.33$ & $6.67^{e} \pm 0.33$ & $1.67^{\mathrm{a}} \pm 0.33$ \\
\hline Dipel 2x (Bt) & $66.70^{\mathrm{e}} \pm 1.43$ & $61.47^{\mathrm{ab}} \pm 2.01$ & $38.52^{\mathrm{bcd}} \pm 2.01$ & $16.67^{b} \pm 0.33$ & $12.33^{b} \pm 0.33$ & $8.00^{\mathrm{a}} \pm 0.00$ & $9.67^{d} \pm 0.33$ & $1.33^{\mathrm{a}} \pm 0.33$ \\
\hline Protecto (Bt) & $73.06^{\mathrm{de}} \pm 6.0$ & $61.39^{\mathrm{ab}} \pm 3.58$ & $38.61^{b d c} \pm 3.85$ & $14.67^{c} \pm 0.33$ & $12.67^{b} \pm 0.67$ & $2.00^{b} \pm 0.00$ & $11.33^{c} \pm 0.33$ & $1.33^{\mathrm{a}} \pm 0.33$ \\
\hline Spinosad & $78.61^{c d} \pm 2.9$ & $67.06^{\mathrm{a}} \pm 1.03$ & $32.94^{d} \pm 1.03$ & $16.67^{b} \pm 0.33$ & $14.33^{\mathrm{a}} \pm 0.58$ & $2.00^{b} \pm 0.00$ & $12.67^{b} \pm 0.33$ & $1.67^{\mathrm{a}} \pm 0.33$ \\
\hline Emamectin benzoate & $75.55^{\text {de }} \pm 3.17$ & $45.92^{d} \pm 0.23$ & $54.08^{a} \pm 0.23$ & $17.33^{\mathrm{ab}} \pm 0.33$ & $15.33^{a} \pm 0.33$ & $2.00^{b} \pm 0.00$ & $13.67^{\mathrm{ab}} \pm 0.33$ & $1.67^{\mathrm{a}} \pm 0.33$ \\
\hline Chlorpyrifos & $91.63^{\mathrm{ab}} \pm 1.85$ & $54.44^{\mathrm{bcd}} \pm 1.0$ & $45.56^{\mathrm{abc}} \pm 1.0$ & $16.67^{b} \pm 0.33$ & $15.00^{\mathrm{a}} \pm 0.58$ & $1.00^{c} \pm 0.00$ & $14.00^{\mathrm{a}} \pm 0.00$ & $1.67^{\mathrm{a}} \pm 0.33$ \\
\hline Indoxacarb) & $86.00^{b c} \pm 1.0$ & $54.44^{\mathrm{bcd}} \pm 1.0$ & $36.89^{c d} \pm 5.35$ & $16.67^{b} \pm 0.33$ & $15^{\mathrm{a}} \pm 0.58$ & $1.00^{c} \pm 0.00$ & $14.00^{\mathrm{a}} \pm 0.00$ & $1.67^{\mathrm{a}} \pm 0.33$ \\
\hline
\end{tabular}

Values marked with the same letters are not significantly different $(P>0.05$ : Duncan's multiple range test)

gave the highest number of eggs per female (274.03 \pm 24.69 eggs). The females laid $363.67 \pm 0.09$ and $215.53 \pm$ 79 eggs/female, respectively, when untreated females mated with treated males with chlorpyrifos or indoxacarb (Fig. 1b).

Considering the number of eggs that actually hatch, fertility \%, (Fig. 1b), in case of mating treated female + treated male results, indicated that emamectin benzoate and chlorpyrifos had a slight effect on fertility percentage than untreated females and males. In addition, chlorpyrifos and indoxacarb showed the same results in results in mating (Fig. 1b, c).

The abovementioned data showed that the larvae survived after exposure to sub-lethal concentration $\left(\mathrm{LC}_{30}\right)$ of the tested bio-insecticides that had a significant reduction in developmental rate including larval, pupal duration, pupal weight, and pupation $\%$ of 2 nd instar larvae till emergence comparing to chlorpyrifos and indoxacarb. This finding is expected because chlorpyrifos is an inhibitor for cholinesterase activity. Also, indoxacarb acts by blocking sodium channel and caused hyperpolarization. This means that both compounds have acute neurotoxic effects. However, $B t$ formulations had long acting effects, and this action gave chance to enhance their latent effects. In contrast, in some other studies, it was found that sub-lethal concentrations of indoxacarb (Wang et al. 2011) on P. xylostella inhibited insect development. In the present study, the highest reduction percentage in the development of $T$. absoluta including larval and pupal durations, pupal mortality, pupation\%, and emergence\% occurred in case of using Lepinox or Dipel $2 \times$ formulation of Bt. Both bioinsecticides, $B t$ or spinosad (tracer) insecticides, showed a high efficacy in controlling larvae of $T$. absoluta (Hamdy et al. 2013; Khidr et al. 2013 and Hashemitassuji et al. 2014). Obtained results were in agreement with (Moustafa et al. 2016) who demonstrated the effect of emamectin benzoate and spinosad on cabbage moth, Mamestra brassicae larvae, and found a significant increase in larval and pupal durations than control with a significant decrease in adult emergency percentage than control.

Table 5 Malformations $\% \pm$ SE of Tuta absoluta after treated the 2 nd instar larvae with $L_{30}$ value of the tested bio-and chemical insecticides

\begin{tabular}{|c|c|c|c|c|c|c|c|}
\hline \multirow{2}{*}{$\begin{array}{l}\text { Bio-and chemical } \\
\text { insecticides } \\
\text { formulations }\end{array}$} & \multirow[b]{2}{*}{ Larval deformation \% } & \multirow[b]{2}{*}{ Pupal deformation \% } & \multirow{2}{*}{$\begin{array}{l}\text { Normal } \\
\text { pupae \% }\end{array}$} & \multicolumn{2}{|c|}{ Deformation adults } & \multicolumn{2}{|l|}{ Normal adults } \\
\hline & & & & Female \% & Male \% & Female \% & Male \% \\
\hline Control & $0.00^{c} \pm 0.00$ & $0.00^{b} \pm 0.00$ & $100.00^{a} \pm 0.00$ & $0.00 c \pm 0.00$ & $1.52^{c} \pm 1.52$ & $100.00^{\mathrm{a}} \pm 0.00$ & $98.48^{a} \pm 1.52$ \\
\hline Lepinox (Bt) & $28.33^{a} \pm 0.33$ & $10.83^{\mathrm{a}} \pm 2.49$ & $71.67^{d} \pm 0.33$ & $7.90 b^{c} \pm 1.06$ & $11.73^{b} \pm 1.9$ & $92.10^{\mathrm{bc}} \pm 1.06$ & $88.27^{b} \pm 1.9$ \\
\hline Dipel 2x (Bt) & $10.48^{c} \pm 1.91$ & $4.29 a^{b} \pm 2.51$ & $89.52^{b} \pm 1.91$ & $9.20 b^{c} \pm 2.06$ & $18.70^{\mathrm{ab}} \pm 4.06$ & $90.8^{b c} \pm 20.6$ & $81.30^{b c} \pm 4.06$ \\
\hline Protecto (Bt) & $18.05^{b} \pm 6.09$ & $4.51^{\mathrm{ab}} \pm 2.77$ & $84.98^{c} \pm 6.12$ & $13.49^{b} \pm 3.71$ & $11.43^{b} \pm 5.95$ & $86.51^{c} \pm 3.71$ & $88.57^{b} \pm 5.95$ \\
\hline Spinosad & $0.00^{c} \pm 0.00$ & $2.63^{b} \pm 2.59$ & $100.00^{a} \pm 0.00$ & $2.56^{\mathrm{cd}} \pm 2.56$ & $0.00^{c} \pm 0.00$ & $73.44^{\mathrm{ab}} \pm 2.56$ & $100.00^{\mathrm{a}} \pm 0.00$ \\
\hline Emamectin benzoate & $2.85^{\mathrm{C}} \pm 1.43$ & $6.8 a^{b} \pm 2.59$ & $97.15^{\mathrm{a}} \pm 1.43$ & $38.42^{a} \pm 3.24$ & $26.85^{a} \pm 3.34$ & $61.58^{\mathrm{e}} \pm 3.24$ & $73.15^{c} \pm 3.34$ \\
\hline Chlorpyrifos & $0.00^{c} \pm 0.00$ & $0.00^{b} \pm 0.00$ & $100.00^{\mathrm{a}} \pm 0.00$ & $0.00^{c} \pm 0.00$ & $0.00^{c} \pm 0.00$ & $100.00^{\mathrm{a}} \pm 0.00$ & $100.00^{a} \pm 0.00$ \\
\hline Indoxacarb & $0.00^{c} \pm 0.00$ & $0.00^{b} \pm 0.00$ & $100.00^{a} \pm 0.00$ & $0.00^{c} \pm 0.00$ & $0.00^{c} \pm 0.00$ & $100.00^{\mathrm{a}} \pm 0.00$ & $100.00^{a} \pm 0.00$ \\
\hline
\end{tabular}

Values marked with the same letters are not significantly different $(P>0.05$ : Duncan's multiple range test) 
(A)

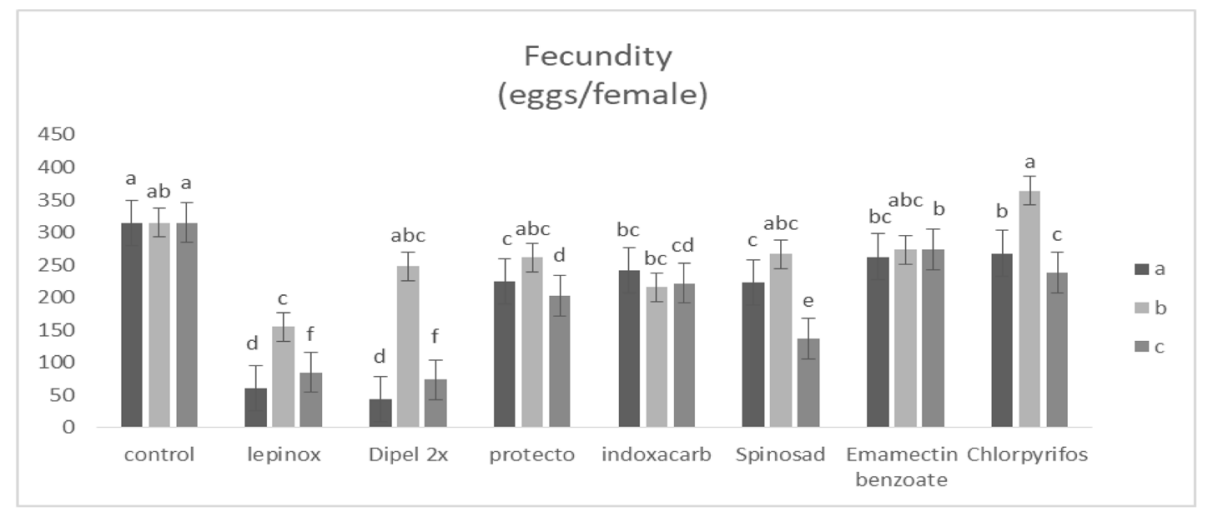

(B)

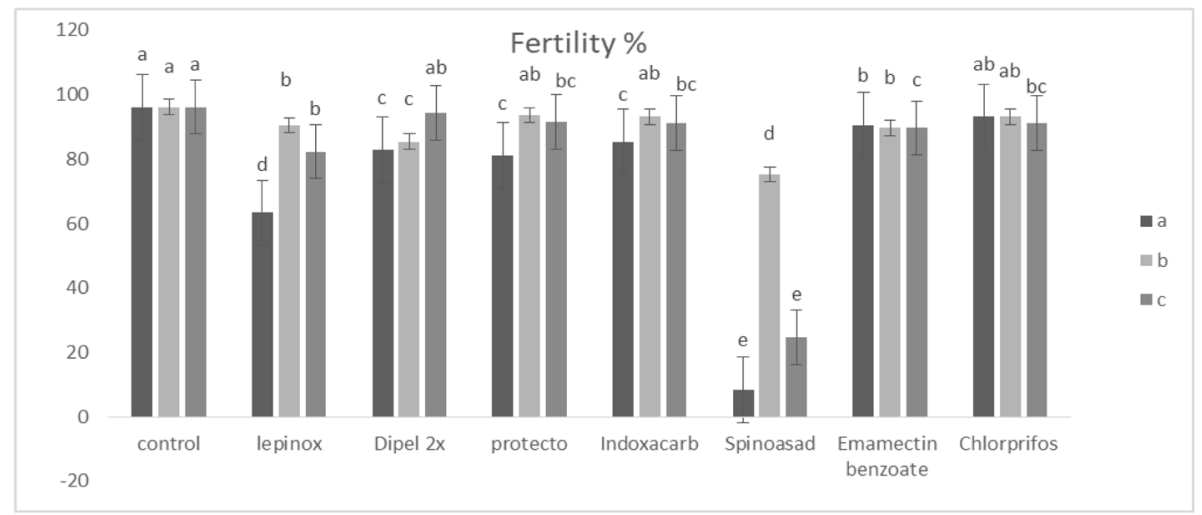

Fig. 1 Mean \pm SE of fecundity (eggs/female) (a) and fertility \% (b) of Tuta absoluta after treated the 2nd instar larvae to LC30 value of the tested bio-and chemical insecticides. a Mating group between treated female + treated male. b Mating group between treated female + untreated male. c Mating group between untreated female + treated male. Different letters on the bars of the histogram showed significant different between treatments

\section{Conclusions}

This study elucidated the efficiency and sub-lethal effects of different bio-insecticide formulations against the tomato leaf miner, T. absoluta. The significance of the results that the bio-insecticides, $B t$ formulations and emamectin benzoate, had a good potential against $T$. absoluta and is recommended to be effectively used in the pest management. Further evaluation under field conditions is still needed.

\section{Acknowledgements}

The authors are grateful to the Academy of Scientific Research \& Technology, Egypt, for funded this research as a part of Grant of Scientists for Next Generation (Dr. SNG5).

\section{Authors' contributions}

The authors carried out all the experiments including the bioassay tests, analytical part, analysis of data, and write the manuscript. The authors read and approved the final manuscript.

\section{Funding}

This research was supported by Academy of Scientific Research \& Technology, Egypt.

\section{Availability of data and materials}

All data of the study have been presented in the manuscript and the materials which are used in this study are highly quality and grade.

Ethics approval and consent to participate

Not applicable.

\section{Consent for publication}

This study does not contain any individual person's data.

\section{Competing interests}

The authors declare that they have no competing interests.

Received: 19 February 2020 Accepted: 3 June 2020

Published online: 18 June 2020

\section{References}

Abbott WS (1925) A method for computing the effectiveness of an insecticide. J Econ Entomol 18:265-267

CFIA. 2010. Tomato leaf miner- Tuta absoluta. Pest. Fact. Sheet [Internet]. Available from http:// www.inspection.gc.ca/english/plaveg/pestrava/tutabs/ tech/tutabse.shtml

Chen X, Ma K, Li F, Liang P, Liu Y, Guo T, Song D, Desneux N, Gao X (2016) Sublethal and transgenerational effects of sulfoxaflor on the biological trout of the cotton aphid, Aphis gossypii Glover (Hemiptera: Aphidadae). Ecotoxicology 10:1841-1848 
Cutler CG, Ramanaidu K, Astakie T, Isman MB (2009) Green peach aphid, Myzus persicae (Hemiptera: Aphididae), reproduction during exposure to sublethal concentrations of imidacloprid and azadirachtin. Pest Manag. Sci. 65:205-209

Deleva EA, Harizanova VB (2014) Efficacy evaluation of insecticides on larvae of the tomato borer Tuta absoluta, Meyrick (Lepidoptera: Gelechiidae) under laboratory Conditions. Journal of International Scientific Publications: Agriculture and Food 2:158-164

el Tantawy MA, Salem MS (1976) Morphogenetic activity of the insect growth regulator pH 60-40 in Spodoptera littoralis Bull. Agric., Cairo Univ. 27:252-266.

Gacemi A, Guenaoui Y (2012) Efficacy of emamectin benzoate on Tuta absoluta Meyrick (Lepidoptera: Gelechiidae) infesting a protected tomato crop in Algeria. Academic Journal of Entomol 5:37-40

Galdino TVD, Picanço MC, Morais EGF, Silva NR, Silva GA, Lopes RMC (2011) Bioassay method for toxicity studies of insecticide formulations to Tuta absoluta (Meyrick, 1917). Ciênc. agrotec. Lavras 35:869-877

Garcia MF, Vercher R (2010) Ecology, sampling and economic threshold of Tuta absoluta (Meyrick). Phytoma España 20:23-26 (in Spanish)

Giustolin TA, Vendramim JD, Alves SB, Vieira SA, Pereira RM (2001) Susceptibility of Tuta absoluta (Meyrick) (Lep., Gelechiidae) reared on two species of Lycopersicon to Bacillus thuringiensis var. kurstaki. J. Appl. Entomol 125:551556

Hafsi A, Abbes K, Chermiti B, Nasraoui B (2012) Response of the tomato miner Tuta absoluta (Lepidoptera: Gelechiidae) to thirteen insecticides in seminatural conditions in Tunisia. Bulletin OEPP/EPPO Bulletin 42:312-316

Hamdy E, Hanafy M, Walaa E-S (2013) Efficacy of bio-and chemical insecticides in the control of Tuta absoluta (Meyrick) and Helicoverpa armigera (Hübner) infesting tomato plants. Aust J Basic Appl Sci 7:943-948

Hashemitassuji A, Safaralizadeh MH, Aramideh S, Hashemitassuji Z (2014) Effects of Bacillus thuringiensis var. kurstaki and Spinosad on three larval stages $1^{\text {st }}$, $2^{\text {nd }}$ and $3^{\text {rd }}$ of tomato borer, Tuta absoluta (Meyrick) (Lepidoptera: Gelechiidae) in laboratory conditions. Archives of Phytopathology and Plant Protection 10:1-10

Khidr AA, Gaffar SA, Maha S, Nada A, Taman A, Fathia A, Salem A (2013) New approaches for controlling tomato leaf miner, Tuta absoluta (Meyrick) in tomato fields in Egypt. Egypt J Agric Res 91:335-348

López JD, Latheef MA, Hoffman WC (2010) Effect of emamectin benzoate on mortality, proboscis extension, gustation and reproduction of the corn earworm, Helicoverpa zea. Journal of Insect Science 10:1-16

Mohammed AS (2010) New record for leaf miner, Tuta absoluta (Lepidoptera: Gelechiidae) infested tomato plantations in Kafr El-Sheikh region. J. Agric. Res. Kafer El-Sheikh Univ. 36:238-239

Moustafa MAM, Kakai A, Awad M, Fonagy A (2016) Sublethal effects of spinosad and emamectin benzoate on larval development and reproductive activities of the cabbage moth, Mamestra brassicae L. (Lepidoptera: Noctuidae). Crop Protection 90:197-204

Palma L, Muñoz D, Berry C, Murillo J, Caballero P (2014) Bacillus thuringiensis Toxins: an Overview of Their Biocidal Activity. Toxins 6:3296-3325

Rausell C, Martinez-Ramirez AC, Garcia-Robles I, Real MD (2000) A binding site for Bacillus thuringiensis Cry1 Ab toxin is lost during larval development in two forest pests. Appl Environ Microbiol 66:1553-1558

Retta AN, Berhe DH (2015) Tomato leaf miner - Tuta absoluta (Meyrick), a devastating pest of tomatoes in the highlands of Northern Ethiopia: a call for attention and action. Res J Agric Environ Manag 4:264-269

Sayed MMA, Behle RW (2017) Evaluating a dual microbial agent biopesticide with Bacillus thuringiensis var. kurstaki and Beauveria bassiana blastospores. Biocontrol Science and Technology, DOl: https://doi.org/10.1080/09583157. 2017.1303662

Wang GL, Huang XL, Wei HY, Fadamiro HY (2011) Sublethal effects of larval exposure to indoxacarb on reproductive activities of the diamondback moth, Plutella xylostella (L.) (Lepidoptera: Plutellidae). Pesticide Biochemistry and Physiology 101:227-231

\section{Publisher's Note}

Springer Nature remains neutral with regard to jurisdictional claims in published maps and institutional affiliations.

\section{Submit your manuscript to a SpringerOpen ${ }^{\circ}$ journal and benefit from:}

- Convenient online submission

- Rigorous peer review

- Open access: articles freely available online

- High visibility within the field

- Retaining the copyright to your article

Submit your next manuscript at $\boldsymbol{\nabla}$ springeropen.com 